\title{
ANALISIS PROSES PEMBUATAN PATI UBI KAYU (TAPIOKA) BERBASIS NERACA MASSA
}

\author{
ARNIDA MUSTAFA \\ Politeknik Pertanian Negeri Pangkep \\ Korespondensi : J1. Poros Makassar-Parepare km 83, Mandalle, Kabupaten Pangkep, \\ Sulawesi Selatan \\ E-mail:Orangestip_nida@yahoo.com
}

\begin{abstract}
Tapioca is starch that is extracted from cassava with characteristic no sweet, undissolved in cold water, form tickle gel in hot water. Tapioca produced from by some process :remove pell of cassava, cleaning, scraping, separation, precipitating, dryng, grinding and become tapioca. the aim of this research has amed to analyze the production of cornmeal by mass balance technology. the process of patiubikayu making by using cassava $2007 \mathrm{~g}$ and produces patiubikayu 376,2 $\mathrm{g}$ (with 14\% water content).
\end{abstract}

\section{Keywords :tapioca, mass balance}

\section{PENDAHULUAN}

Indonesia memiliki iklim tropis yang memberikan keuntungan bagi masyarakat Indonesia untuk pengembangan dan budidaya ubi kayu (Manihot utilissima) dalam pilar ketahanan pangan, sehingga Indonesia dikenal sebagai salah satu bahan pangan yang cukup penting. Selain dimanfaatkan sebagai bahan pangan ubi kayu juga digunakan sebagai bahan baku industri, baik industri pangan maupun non pangan.

Ubi kayu merupakan komoditas tanaman pangan ketiga Indonesia setelah padi dan jagung sekaligus sumber kalori pangan termurah dan cukup ketersediaannya. Ubi kayu Indonesia terutama digunakan untuk bahan pangan $(58 \%)$, bahan baku industri $(28 \%)$, ekspor dalam bentuk gaplek $(8 \%)$ dan pakan $(2 \%)$ (Dir. Kacang-kacangan \& Umbi-umbian, 2006). Pengolahan ubi kayu menjadi beberapa produk olahan merupakan upaya untuk mendukung program ketahanan pangan \& diversifikasi pangan serta menjadi salah satu solusi masalah ketergantungan dan kelangkaan satu bahan pangan pokok. Pengolahan ubi kayu menjadi tepung tapioka merupakan salah satu langkah strategis \& ekonomis bagi pengembangan ubi kayu menjadi produk olahan.

Tepung tapioka dibuat dari hasil penggilingan ubi kayu yang dibuang ampasnya.Ubi kayu tergolong polisakarida yang mengandung pati dengan kandungan amilopektin yang tinggi tetapi lebih rendah daripada ketan yaitu amilopektin $83 \%$ dan amilosa 17 $\%$, sedangkan buah-buahan termasuk polisakarida mengandungselulosadanpektin

(Winarno, 2004).

Industri tepung (starch) adalah salah satu bidang industri yang usianya tua dan merupakan cabang dari industri hilir ubi kayu yang memproses ubi kayu segar menjadi starch. industri tepung ini merupakan komoditi dagang langsung dan juga merupakan sumber bahan baku dari industri hilir starch. Begitu pentingnya industri starch, sehingga dalam satu abad terakhir ini, perkembangan industri hilir starch sangat pesat, seirama dengan perkembangan bahan baku modern yang mendatangkan era industri hilir starch. Produksi starch dunia (termasuk starch yang dibuat dari jagung, gandum, kentang, ubi merah dan ubi kayu), pada tahun 1976 hanya mencapai 7,7 juta ton/tahun pada tahun terakhir ini telah mencapai 30 juta ton/tahun, starch jagung mendominasi $70 \%$ dan starch ubi kayu hanya 8-9\%. Tujuan 
dari kajian ini adalah untuk mengetahui proses pembuatan pati ubi kayu dan menganalisis pembuatan pati ubi kayu dengan teknik neraca massa.

\section{METODE PENELITIAN}

Bahan-bahan yang digunakan pada penellitian ini adalah ubi kayu $(2 \mathrm{~kg})$ dan air. Alat-alat yang digunakan pada penelitian ini adalah timbangan, pisau, parutan, baskom, kain saring, oven dan desikator.

Diagram alir pada pembuatan tepung pati ubi kayu dapat dilihat pada gambar 1.

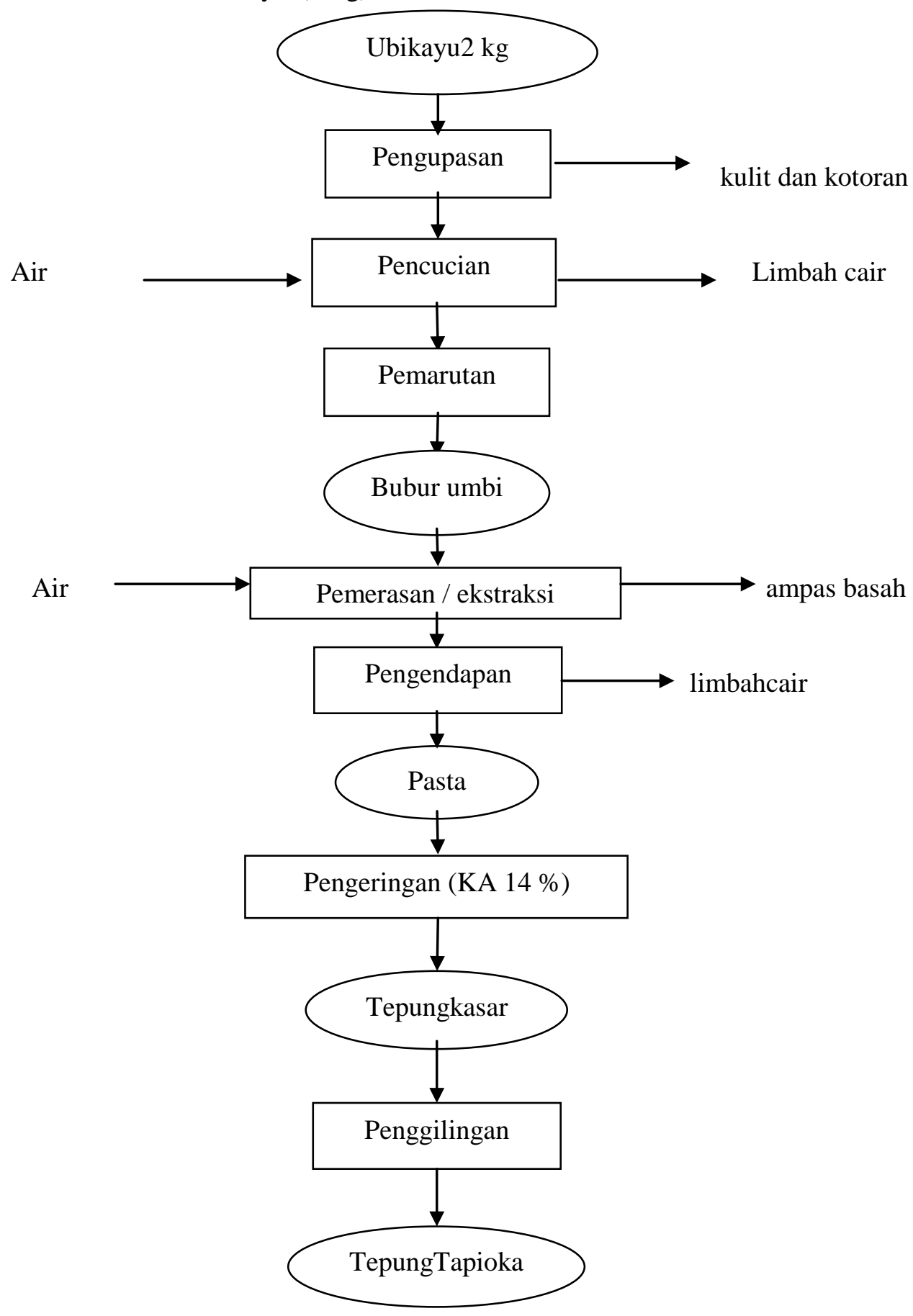

Gambar 1. Diagram Alir Pembuatan Tepung Pati Ubi Kayu 
Tahapan pembuatan pati ubi kayu adalah proses penimbangan berat awal ubi kayu atau singkong. Daging ubi kayu atau singkong dipisahkan dari kulitnya dengan cara pengupasan. Selama pengupasan dilakukan sortasi bahan baku dengan pemilihan singkong atau ubi kayu yang bagus. Daging ubi kayu dan kulit singkong di timbang dengan cara terpisah.Daging ubi kayu di cuci sampai bersih di dalam bak yang berisi air untuk memisahkan kotoran yang menempel pada ubi kayu.Daging ubi kayu diparut secara manual (parutan biasa) sampai halus menjadi bubur umbi.Umbi yang sudah diparut ditimbang kembali, kemudian ditambahkan air sehingga terbentuk bubur dan diremas-remas agar pati lebih banyak yang terlepas dari sel umbi.Bubur umbi kemudian disaring dengan kain saring sehingga pati lolos dari saringan sebagai suspensi pati, dan serat tertinggal pada saring. Suspensi pati yang diperoleh kemudian ditampung pada wadah pengendapan.Suspensi pati hasil ekstraksi diendapkan di dalam wadah pengendapan selama 12 jam. Pati akan mengendap sebagai pasta. Cairan di atas endapan dialirkan dan ditampung di dalam wadah yang lain, dan pasta dikeringkan dengan alat pengering (oven) sampai kadar air dibawah $14 \%$.Produk yang telah kering atau tepung kasar kemudian digiling sampai (sekurang-kurangnya 80 mesh) menjadi tepung tapioka.

\section{HASIL DAN PEMBAHASAN}

\section{Proses Pengolahan Tepung Ubi Kayu (Tapioka)}

Proses pembuatan tapioka secara umum terdiri atas pengupasan kulit, pencucian, pemarutan, pemerasan atau ekstraksi, pengendapan, penggilingan atau penepungan. Menurut Lingga (1993), ada empat tahap pembuatan tepung tapioka, yaitu:

1. Tahap pemecahan sel dan pemisahan butiran pati dari unsur lain yang tidak larut. Termasuk dalam kegiatan ini pengupasan, pencucian, pemarutan dan penyaringan.
2. Tahap kedua pengambilan pati dengan penambahan air, termasuk juga dalam perlakuan ini pengendapan dan pencucian.

3. Tahap ketiga pembuangan/penghilangan air. Untuk membantu kegiatan ini bisa dilakukan dengan pengeringan melalui panas dan pemusingan.

4. Tahap terakhir adalah melakukan penepungan agar diperoleh tepung yang dikehendaki. Termasuk dalam urusan ini penghancuran dan beberapa pekerjaan lainnya.

Pengolahan ubi kayu menjadi tepung dimulai dari sortasi ubi kayu yaitu pemilihan ubi kayu yang bagus. Ubi kayu yang jelek atau rusak dipisahkan dan tidak diikutkan pada proses selanjutnya. Hal ini untuk menghindari rasa pahit dan keracunan yang disebabkan oleh asam sianida yang ada dalam ubi kayu. Ubi kayu menghasilkan umbi yang mengandung pati. Pada umbi ubi kayu terdapat racun asam sianida. Pada ubi kayu manis kandungan asam sianida pada umbi sangat rendah sehingga tidak dapat menimbulkan efek keracunan bagi yang mengkonsuminya. Sedangkan ubi kayu pahit kandungan asam sianida sangat tinggi sehingga dapat meimbulkan keracunan bagi yang mengkonsumsinya (Anonim, 2007).

Tahapan proses selanjutnya adalah pengupasan kulit yaitu daging ubi kayu dipisahkan dengan kulitnya dengan cara pengupasan. Bagian-bagian umbi yang tidak berguna dihilangkan karena akan menggangu proses pengolahan. Selanjutnya proses pencucian dilakukan dengan cara meremas-remas ubi kayu di dalam bak yang berisi air, tujuannya adalah untuk memisahkan kotoran yang menempel pada singkong. Pencucian ini dilakukan dengan mengalirkan air ke arah yang berlawanan dengan arah aliran umbi; atau dilakukan dalam bak dimana air harus sering diganti (sehingga dibutuhkan banyak air) (Anonim, 2007).

Tahapan proses selanjutnya adalah pemarutan dilakukan dengan secara manual yaitu dengan menggunakan parutan biasa. Umbi diparut halus sampai 
menjadi bubur umbi. Tujuannya untuk memecah dinding sel agar butir pati yang ada di dalamnya dapat keluar. Setelah bubur ditambah air (4 kg) kemudian dilakukan pemerasan atau ekstraksi suspensi pati dengan menggunakan kain saring sehingga pati dapat lolos dari saringan sebagai suspensi pati. Pemerasan dilakukan dengan cara meremas-remas bubur pati sehingga patinya dapat keluar. Penyaringan dilakukan menggunakan air yang cukup sampai air saringan jernih untuk memisahkan butir tepung pati dari ampas. Pati yang telah tersuspensi dalam air saringan selanjutnya diendapkan sesegera mungkin.

Setelah proses pemerasan (ekstraksi) dan penyaringan dilakukan proses pengendapan. Suspensi pati hasil ekstraksi ditampung dalam wadah pengendapan. Tujuan dari pengendapan yaitu untuk memisahkan bagian atau komponen air dengan asta. Air dibagian atas endapan dipisahkan dengan endapan, air tersebut disimpan di wadah yang lain. Sedangkan endapannya diambil dan dikeringkan.

Pengeringan dilakukan dengan menggunakan oven pada suhu $68^{\circ} \mathrm{C}$ sampai diperoleh kadar air di bawah $14 \%$. Maksud dan tujuan pengeringan adalah untuk mengurangi kandungan air sehingga diperoleh tapioka yang kering. Kadar air yang terlalu tinggi akan memudahkan tumbuhnya jamur/cendawan dan menimbulkan bau yang tidak disukai. Seyogyanya kadar air tapioka hasil pengeringan $13 \%$ namun kisaran kadar air $14,5-17 \%$ masih dapat diterima dalam perdagangan. Standar mutu tapioka untuk faktor kadar air (maksimal) adalah $17 \%$ (Tabel 1).

Hasil pengeringan pasta pati berupa tepung tapioka kasar. Tepung kasar ini selanjutnya digiling dengan menggunakan blender sampai (sekurangkurangnya 80 mesh) menjadi tepung tapioka. Secara visual, warna memegang peranan penting dalam penentuan suatu mutu produk yang dihasilkan. Warna tepung tapioka yang dihasilkan adalah berwarna putih. Hal ini menandakan bahwa kualitas tepung tapioka tersebut memenuhi standart mutu tapioka. Pada dasarnya kualitas tapioka sangat ditentukan oleh beberapa faktor, yaitu :

1. Warna Tepung; tepung tapioka yang baik berwarna putih.

2. Kandungan Air; tepung harus dijemur sampai kering benar sehingga kandungan airnya rendah.

3. Banyaknya serat dan kotoran; usahakan agar banyaknya serat dan kayu yang digunakan harus yang umurnya kurang dari 1 tahun karena serat dan zat kayunya masih sedikit dan zat patinya masih banyak.

4. Tingkat kekentalan; usahakan daya rekat tapioka tetap tinggi. Untuk ini hindari penggunaan air yang berlebih dalam proses produksi.

\section{Neraca Massa Proses Ekstraksi Ubi Kayu}

Neraca massa digunakan untuk melihat jumlah bahan yang masuk dengan bahan yang keluar dari suatu proses berdasarkan hukum kekekalan massa, yaitu jumlah alliran masuk sama dengan jumlah aliran keluar. prinsip dasar yang digunakan apabila dalam suatu proses tidak ada akumulasi dalam peralatan prosessing, maka jumlah bahan yang masuk akan sama dengan jumlah bahan keluaran. hal ini berarti bahwa tidak ada bahan yang hilang dan tidak ada penambahan bahan dari luar.

Suatu sistem apapun, jumlah materi akan tetap walaupun terjadi perubahan bentuk ataupun keadaan fisik. oleh sebab itu dalam suatu proses pengolahan akan terjadi jumlah bahan yang masuk akan sama dengan jumlah bahan yang keluar sebagai produk yang dikehendaki ditambah dengan jumlah yang hilang atau produk samping (wirakartakusumah, 1989). Berikut disajikan tabel input output dari proses pembuatan pati ubi kayu.

Neraca massa proses pembuatan pati ubi kayu pada setiap tahapan dapat dilihat pada gambar 2 . 
Tabel 1 Standar Mutu Tapioka (SNI 01-3451-1994)

\begin{tabular}{|c|c|c|c|c|}
\hline \multirow{2}{*}{ No } & \multirow{2}{*}{ PersyaratanMutu } & \multicolumn{3}{|c|}{ Mutu } \\
\hline & & I & II & III \\
\hline 1 & - Kadar air (\% maks.) & 15 & 15 & 15 \\
\hline 2 & - Kadar abu (\% maks.) & 0,60 & 0,60 & 0,60 \\
\hline 3 & - Serat \& kotoran (\% maks.) & 0,60 & 0,60 & 0,69 \\
\hline 4 & - Derajat keasaman( IN NaOH / $100 \mathrm{~g}$ ) & $<3 \mathrm{ml}$ & $<3 \mathrm{ml}$ & $<3 \mathrm{ml}$ \\
\hline 5 & - Kadar HCN (\% maks.) & negatif & negatif & negatif \\
\hline 6 & - Derajat putih $(B A S 04=100)$ & 94,5 & 92,0 & 92,0 \\
\hline 7 & - Kekentalan(o Engler $)$ & $3-4$ & $2,5-3$ & $<2,5$ \\
\hline
\end{tabular}

Sumber : SNI, 1992.

Tabel 2. Rekapitulasi Neraca Massa Ekstraksi Ubi Kayu

\begin{tabular}{|c|c|c|c|}
\hline No. & PROSES & INPUT & OUTPUT \\
\hline \multirow{2}{*}{1.} & Pengupasan & Ubi Kayu $=2007 \mathrm{~g}$ & $\begin{array}{l}\text { Umbi }=1653 \mathrm{~g} \\
\text { Kulit }=354 \mathrm{~g}\end{array}$ \\
\hline & Total & $2007 \mathrm{~g}$ & $2007 \mathrm{~g}$ \\
\hline 2. & Pencucian & $\begin{array}{l}\text { Umbi }=1653 \mathrm{~g} \\
\text { Air }=1000 \mathrm{~g}\end{array}$ & $\begin{array}{l}\text { Air }+ \text { Kotoran }=920 \mathrm{~g} \\
\text { Umbi Bersih }=1733 \mathrm{~g}\end{array}$ \\
\hline \multirow[t]{2}{*}{3.} & $\begin{array}{c}\text { Total } \\
\text { Pemarutan }\end{array}$ & $\begin{array}{c}\mathbf{2 6 5 3} \mathbf{~ g} \\
\text { Umbi Bersih }=1733 \text { g }\end{array}$ & $\begin{array}{l}\quad \mathbf{2 6 5 3} \mathbf{g} \\
\text { Bubur Umbi }=1609 \mathrm{~g} \\
\text { Loss }=124 \mathrm{~g}\end{array}$ \\
\hline & Total & $\begin{array}{c}\mathbf{1 7 3 3} \mathbf{g} \\
\text { Bubur Umbi }=1609 \mathrm{~g}\end{array}$ & $\begin{array}{rl}\mathbf{1 7 3 3} & \mathbf{g} \\
\text { Onggok }=992,5 \mathrm{~g}\end{array}$ \\
\hline \multirow[t]{2}{*}{4.} & Pemerasan & Air $=4000 \mathrm{~g}$ & $\begin{array}{l}\text { Suspensi Pati }=4388,5 \mathrm{~g} \\
\text { Loss }=228 \mathrm{~g}\end{array}$ \\
\hline & Total & $5609 \mathrm{~g}$ & $5609 \mathrm{~g}$ \\
\hline 5. & Pengendapan & Suspensi Pati $=4388,5 \mathrm{~g}$ & $\begin{array}{l}\text { Air }=3900 \mathrm{~g} \\
\text { Pasta Pati }=488,5 \mathrm{~g}\end{array}$ \\
\hline 6. & $\begin{array}{c}\text { Total } \\
\text { Pengeringan }\end{array}$ & $\begin{array}{c}\mathbf{4 3 8 8 , 5} \mathbf{~ g} \\
\text { Pasta Pati }=488,5 \mathrm{~g}\end{array}$ & $\begin{array}{l}\mathbf{4 3 8 8 , 5} \mathbf{g} \\
\text { Tepung Kasar }=376,2 \mathrm{~g} \\
\text { Air }=112,3 \mathrm{~g}\end{array}$ \\
\hline \multirow{2}{*}{7.} & $\begin{array}{c}\text { Total } \\
\text { Penggilingan }\end{array}$ & $\begin{array}{c}\mathbf{4 8 8 , 5} \mathbf{g} \\
\text { Tepung Kasar }=376,2 \mathrm{~g}\end{array}$ & $\begin{array}{l}\quad \mathbf{4 8 8 , 5} \mathbf{g} \\
\text { Tepung Tapioka }=374,2 \mathrm{~g} \\
\text { Loss }=2 \mathrm{~g}\end{array}$ \\
\hline & $\begin{array}{c}\text { Total Rendemen } \\
\text { Akhir } \\
\end{array}$ & $376,2 \mathrm{~g}$ & $376,2 \mathrm{~g}$ \\
\hline
\end{tabular}

Rendemen yang dihasilkan dari 2,007 kg ubi kayu pada pembuatan tepung tapioka adalah $18,744 \%$. Tinggi atau rendahnya rendemen pada suatu produk juga ditentukan oleh bahan baku yang digunakan, menurut Direktorat Pengolahan Hasil Pertanian (2012), bahwa Varietas ubi kayu yang digunakan dalam pembuatan pati tapioka dapat berasal dari semua varietas. Umbi tidak tahan disimpan sehingga perlu diperhatikan pada saat panen, pengangkutan, dan penanganan segar. Dalam waktu 24 jam setelah pemanenan ubi kayu harus segera diproses. Apabila terlambat memproses akan terjadi "kepoyoan", yaitu ubi berwarna kecoklatan, sehingga menurunkan mutu tapioka. Mutu tapioka sangat ditentukan oleh mutu ubi kayu segar.

Faktor pengolahan juga sangat berpengaruh pada rendemen yang dihasilkan, misalnya pada saat pemerasaan yang dilakukan kurang optimal sehingga 
sel pati tidak terekstraksi dengan sempurna. Demikan pula pada proses penggilingan, biasanya pada proses ini apabila tidak ditangani dengan baik maka banyak tepung yang terbuang karena ukuran butiran yang kecil dan halus sehingga mudah keluar akibat tiupan udara melalui celah-celah yang terdapat pada sepanjang aliran tepung sampai pada kemasan.

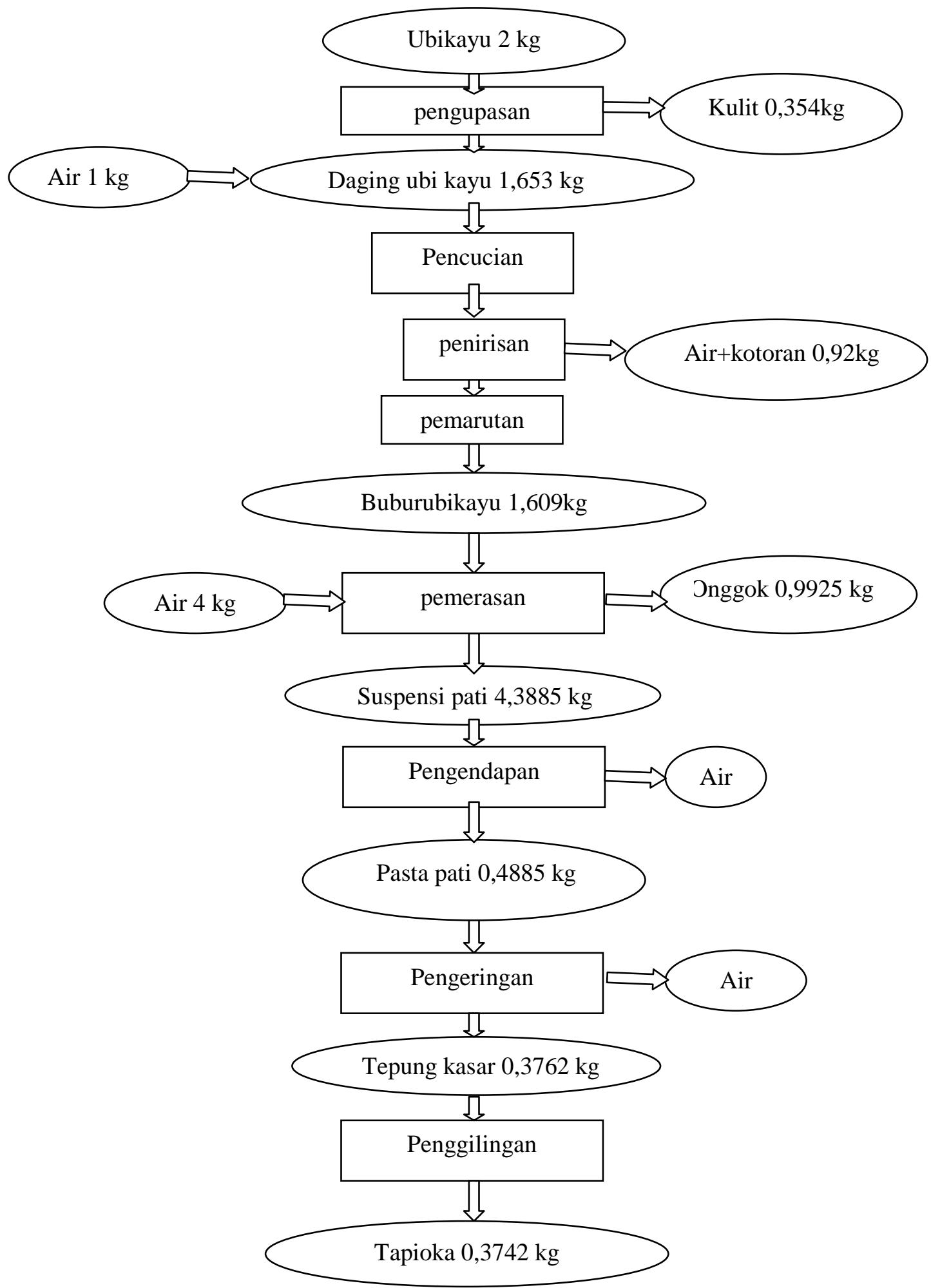

Gambar 2. Neraca Massa Proses Pembuatan Tepung Ubi Kayu 


\section{KESIMPULAN}

Proses pembuatan pati dari ubi kayu dengan menggunakan ubi kayu sebanyak $2.007 \mathrm{~g}$ ubi menghasilkan pati ubi kayu sebanyak 376,2 g (dengan Ka $14 \%$ ). Rendemen ubi kayu yang dihasilkan sebesar $18,744 \%$.

\section{DAFTAR PUSTAKA}

Anonim, 2007, ubi kayu http://www.warintek.com/ubi kayu, 2007, akses Desember 2007.
Direktorat Pengolahan Hasil Pertanian, 2012, Pedoman teknis pengembangan agroindustri tanaman pangan tahun 2002, Jakarta

Lingga, P. 1993. Bertanam Ubi-ubian. Penebar Swadaya. Jakarta.

Wirakartakusumah A. 1989. Prinsip Teknik Pangan. PAU Pangan dan Gizi. IPB, Bogor

Winarno, F. G., 2004. Kimia Pangan dan Gizi. Cetakan ke-XI. PT. Gramedia Pustaka Utama. Jakarta. 